\title{
O modelo legal de família e as tendências atuais: reflexões canônicas e civis
}

\author{
The family legal model and its present tendencies: \\ canonical and civil thoughts
}

\section{Frederico Martins e Silva ${ }^{1}$}

Resumo: O presente artigo traz à luz algumas reflexões acerca da questão "família", apresentando conceitos e abordagens no pensar jurídico, seja canônico ou civil, no atual contexto, numa visão eclesiológica, pastoral e civilística. Inicialmente, tratará do lugar que o direito ocupa no coetus eclesial e da relação da Igreja com o mundo. Seguidamente, falar-se-á do objeto de estudo "família" a partir da compreensão do direito canônico e do direito civil, segundo as tendências da época contemporânea, através de uma compreensão sociológica, eclesiológica e pastoral. Finalmente, abrirá à reflexão o conceito de família, adotado pelo consolidado magistério da Igreja, como também da família cristã e de seu papel no mundo.

\begin{abstract}
The article brings to light some reflections on the question "family", concepts and approaches, in legal thinking, whether canonical or civil, in nowadays age context, in an ecclesiological, pastoral and civilistic view. Initially, it will deal with the place that law occupies in the ecclesial coetus and the relationship that the Church has with the world. Next, we will speak of the object of study "family" from the understanding of canon law and civil law, according to the tendencies of the contemporary age, through a sociological, ecclesiological and pastoral understanding. Finally, it will open up to reflection the concept of the family, adopted by the established magisterium of the Church, as well as of the Christian family and its role in the world.
\end{abstract}

1 Doutor em Direito Canônico e Direito Civil pela Universidade Lateranense (Roma) - reconhecido pela PUC do Rio de Janeiro. Especializado em Bioética pelo Ateneu Pontifício Regina Apostolorum (Roma). Professor no Instituto Superior de Direito Canônico Santa Catarina (Florianópolis-SC), na Faculdade Arquidiocesana de Curvelo, no curso de Direito, Instituto Santo Tomás de Aquino (Belo Horizonte-MG). Reitor e Professor dos Institutos de Filosofia e Teologia do Seminário Arquidiocesano Sagrado Coração de Jesus de Diamantina-MG. Presidente do Tribunal Eclesiástico Interdiocesano e de Apelação de Diamantina - MG. 
Palavras-chaves: Família; direito de família; direito matrimonial canônico; pastoral familiar.

Keywords: Family; family right; canonical marriage law; family pastoral.

\section{Introdução}

O presente artigo tem por escopo estudar o tema família, no momento em que se experimentam transformações profundas nas sociedades humanas. Nestas, a família encontrará lugar primacial na reflexão dos povos, no âmbito de sua consciência coletiva e individual, vez que repousarão nela as tendências atuais de mentalidade e de comportamento.

Urge, portanto, desse modo, a necessidade de se propiciar a discussão do referido tema, qual seja $\mathrm{O}$ modelo legal de família e as tendências atuais, à vista dos debates ocorrentes área jurídica e jurisprudencial, bem como na esfera da reflexão canônica e pastoral, intrínsecos ao modelo legal de família.

Constata-se, inclusive, em um recente pensar filosófico, o findar dos grandes relatos do iluminismo, do idealismo e do marxismo; de uma nova consciência no "depois" da pós-modernidade, um "novo realismo"2. Já alertou o atual Pontífice, que "na cultura dominante ocupa o primeiro lugar aquilo que é exterior, imediato, visível, rápido, superficial, provisório. O real cede o lugar à aparência"” ${ }^{\text {. }}$

Referido contexto constitui desafio para o legislador - seja na esfera comum, seja na canônica - que se depara com fenômenos como "as inseminações e fertilizações artificiais, os úteros de aluguel, as cirurgias de mudança de sexo, os relacionamentos afetivos entre pessoas do mesmo sexo, a clonagem de células e de pessoas" $" 4$ e, consequentemente, os novos modelos de família, na crescente "oferta de felici-

2 Destacam-se no momento Markus Gabriel em $O$ sentido da Existência: para um novo realismo ontológico, Rio de Janeiro: Editora Civilização Brasileira, 2016 e Maurizio Ferraris no seu Manifiesto del nuevo realismo, Santiago: Ariadna Ediciones, 2012.

3 PAPA FRANCISCO, Evangelii Gaudium, A alegria do evangelho, n. 62, São Paulo: Paulinas, 2013, p. 54.

4 GONÇALVEZ, Carlos Roberto. Direito civil brasileiro: Direito de Família. vol 6, Saraiva, São Paulo, 2006, p. 15. 
dade, de realização e sucesso pessoal, em detrimento do bem comum e da solidariedade, desconsiderando as atitudes altruístas, solidárias e fraternas"

É com solicitude que a Igreja e, naturalmente o direito como tal - essa é sua tarefa - vão à busca de soluções e novos caminhos, trazendo para o centro de seu discurso uma relevante e frutuosa reflexão acerca da família. Deste feito mostrar-se-á, inicialmente, a necessidade ainda vigorosa de um pensar jurídico na Igreja para, sucessivamente, trazer à luz o que emerge das tendências atuais no campo do direito civil e do direito canônico, através de uma compreensão sociológica, eclesiológica e pastoral da instituição familial.

Considerando a complexidade do tema, algumas questões se colocam: Encontrará o direito resposta na conservação de modelos tradicionais de família? Saberá o direito, em suas esferas civil e canônica, atender às atuais exigências da sociedade, cumprindo sua função sem prejuízo às peculiaridades da família?

\section{Relação direito e Igreja}

O Senado romano, no quarto século antes de Cristo, nomeou Quinto Fabio para combater os gauleses, na batalha conhecida como Batalha de Ália. Encontrando-se na cidade etrusca de Clúsio, Quinto Fabio atuou, num primeiro momento, como negociador e diplomata. Estando frente a frente com Breno, o chefe dos gauleses, Fábio alegou o Direito a favor de Roma; o gaulês, entretanto, responde com a célebre frase: "o Direito está em nossas armas e todas as coisas são propriedades dos homens valentes" 6 .

Teria ainda o direito algum papel ou função no contexto da Igreja Contemporânea? A Igreja em saída, a Igreja do evangelho e do amor, a Igreja da acolhida? Teria algum sentido a regra de direito numa e para uma comunidade "comunhão", que tem como ligame a vir-

5 CONFERÊNCIA NACIONAL DOS BISPOS DO BRASIL. Diretrizes gerais da ação evangelizadora da Igreja no Brasil: 2015-2019. Brasília: Edições CNBB, 2015, p. 26.

6 Tito Lívio, Historia de Roma desde su fundacion - Ab urbe condita - Libro $V$, Internet. Disponível em: http://historicodigital.com/download/tito $\% 20$ livio $\%$ 20i.pdf, p. 218. 
tude da caridade? Como se pode falar de um autêntico espaço para norma positivada, que subsiste em concomitância com a revelação e o patrimônio de fé, num cenário eclesial de uma Igreja que é "Povo de Deus", "Corpo Místico de Cristo" e "Sacramento"?

Ulpiano, grande jurista romano do segundo século, sugere no Corpus Iuris Civilis de Justiniano: "Ubi societas ibi ius",7.

Por tal afirmação o mencionado escritor alerta que o homem não pode viver alheio aos laços sociais e que, consequentemente, para manter referidos laços, as regras se fazem imprescindíveis. $\mathrm{O}$ direito, neste sentido, orienta as atividades humanas e integra o cotidiano.

A Igreja, como sociedade de pessoas, insere-se nesta seara e não subsistirá fora dela.

O Santo Bispo de Hipona, comentando a carta aos Gálatas (4, 21-31) afirma: "uma parte da cidade terrena se tornou imagem da Cidade celeste, sem um significado próprio, mas símbolo da outra, logo

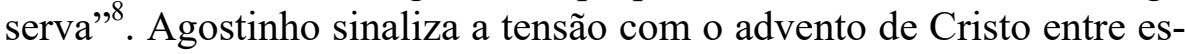
tas duas realidades, a cidade terrena e a cidade celeste. Esta relação de consequência supõe uma distinção entre as duas. Pelo fato de existir implicarão entre as duas, não uma recíproca ignorância, nem absoluta contraposição.

Certamente "uma é finita, a outra sem confins; uma é historicamente dada, a outra eterna; uma conhece a maldade, a injustiça, o conflito; a outra é o reino de bondade, de justiça e de paz"9.

A cidade terrena é imagem e símbolo da outra a qual serve. Nem tudo, porém, na cidade terrena é mal. Essa cidade terrena possui uma perfeição em si mesma, segundo sua própria natureza, que pode ser individuada e constantemente buscada. Da complexa realidade da Igreja transcende a história a sua realidade sacramental, estando profundamente radicada na realidade terrena, expressa em um corpo social juridicamente organizado, peregrinante na história ${ }^{10}$.

7 PARADISO, Massimo, Corso di Instituzioni di Diritto Privato, G. Giappichelli Editore, Torino, 2001, p. 2

8 DALLA TORRE, Giuseppe, La città sul monte, Contributo ad uma teoria canonistica sulle relazioni fra Chiesa e Comunità politica, $2^{\mathrm{a}} \mathrm{ed}$., Editrice Ave, Roma, 2002, p. 11.

9 DALLA TORRE, La città, p. 11.

10 DALLA TORRE, La città, p. 11. 
A Igreja, enquanto comunidade de fiéis, hierarquicamente organizada, como comunidade humana vivente na história, sempre esteve imersa na comunidade política, participando de seus problemas, dores e alegrias.

Em sua dimensão humana e histórica, a Igreja não se apresenta como uma forma estranha às outras formas de agregação humana. Certamente o povo de Deus se mostra, no contexto dos grupos sociais humanos, como fenômeno único e peculiar. É, em certo sentido, a continuação do mistério da encarnação; mas sempre se faz ver, na sua dimensão histórica, como organizada, sistemática, fundada em normas como quaisquer outras que guiam a vida dos corpos sociais. E, nessa tendência relacional com a comunidade humana sempre, curiosamente, foi expressa em termos jurídicos, visto que, com fácil compreensão, temos conhecimento de que o direito postula uma relação, sendo sempre expressão desta relação.

A tradicional doutrina católica sempre viu na Igreja esta dupla realidade, ao mesmo tempo invisível e visível, espiritual e social, carismática e institucional, sacramental e jurídica. Diz a Constituição Pastoral Conciliar Gaudium et Spes:

Nascida do amor do Pai, fundada no tempo por Cristo Redentor e coadunada no Espírito Santo, a Igreja tem um fim salutar e escatológico... Contudo, ela já está presente aqui na terra, composta de homens membros da cidade terrestre, chamados justamente a formarem já na história do gênero humano a família dos filhos de Deus, que deve crescer sempre até a vinda do Senhor. (GS 40).

Como asseverado por João Paulo II, na Carta Apostólica Novo Millennio Ineunte n. 45,

(...) a ciência jurídica, ao estabelecer normas precisas de participação, manifesta a estrutura hierárquica da Igreja e esconjura tentações de arbítrio e injustificadas pretensões, a espiritualidade da comunhão confere uma alma ao dado institucional, ao aconselhar confiança e abertura que corresponde plenamente à dignidade e responsabilidade de cada membro do povo de Deus. 
Discursando na Assembleia das Nações Unidas, em 25 de setembro de 2015, o Papa Francisco asseverou:

A tarefa das Nações Unidas, com base nos postulados do Preâmbulo e dos primeiros artigos da sua Carta constitucional, pode ser vista como o desenvolvimento e a promoção da soberania do direito, sabendo que a justiça é um requisito indispensável para se realizar o ideal da fraternidade universal. Neste contexto, convém recordar que a limitação do poder é uma ideia implícita no conceito de direito ${ }^{11}$.

Logo, ao contrário do que citamos em princípio, acerca do que bravejou Breno dos gauleses, na antiguidade, a Igreja não fundamenta seu direito na força das armas e na vontade de dominar, mas na caridade! Diz o Legislador e promulgador do último código de direito canônico, para a Igreja Latina:

(...) torna-se bem claro, pois, que o objetivo do Código não é, de forma alguma, substituir, na vida da Igreja ou dos fiéis, a fé, a graça, os carismas, nem muito menos a caridade. Pelo contrário, sua finalidade é, antes, criar na sociedade eclesial uma ordem que, dando a primazia ao amor, à graça e aos carismas, facilite, ao mesmo tempo, seu desenvolvimento orgânico na vida, seja da sociedade eclesial, seja de cada um de seus membros ${ }^{12}$.

\section{Família: conceitos e abordagens}

Deste feito, o que o direito tem a dizer da família? Certamente muito. A questão que nos cabe é como o direito fala da família?

Com o cuidado em visualizar o direito como norma de conduta, como regra de comportamento e esquivando-se dos excessos do positivismo jurídico, seja no âmbito civil e de especial modo na canonística, ele deverá "equilibrar-se com o necessário grau de moralidade e

11 PAPA FRANCISCO, Discurso na Assembleia das Nações Unidas. Internet. Disponível em: http://w2.vatican.va/content/francesco/pt/speeches/2015/september/ documents/papa-francesco_20150925_onu-visita.html

12 Constituição Apostólica Sacrae disciplinae Leges, in CÓDIGO DE DIREITO CANÔNICO, $9^{\mathrm{a}}$ ed., Edições Loyola, São Paulo, 2008, p. XV. 
animando-a com o anseio natural de justiça, este dom inato ao ser humano" $" 13$.

No âmbito do direito privado, o direito de família se destaca, enquanto diretamente ligado à vida concreta e diária das pessoas, isso porque "as pessoas provêm de um organismo familiar e conservam-se vinculadas durante a sua existência, mesmo que venham a constituir nova família pelo casamento ou pela união estável"14.

Ela é uma realidade sociológica e constitui a base do Estado, o núcleo fundamental em que repousa toda a organização social. Diz João Paulo II na Familiaris Consortio: "A sociedade e, mais especificamente o Estado, devem reconhecer que a família é uma sociedade que goza de um direito próprio e primordial." (FC 45). Ela vai merecer a mais ampla proteção do Estado.

A Constituição Federal e o Código Civil Brasileiro a ela se reportam e estabelecem a sua estrutura sem, contudo, defini-la. Constata-se, deste modo, uma pluralidade de conceitos tanto no direito, quanto na sociologia.

Constatamos que a

(...) condição atual da instituição da família é um capítulo de sua história evolutiva no ciclo da civilização ocidental, a que não faltam as contribuições da cultura bíblica; da vida doméstica nas Penínsulas helênica e itálica; da estrutura germânica que importamos indiretamente através de seu impacto sobre o Império Romano ao tempo das invasões bárbaras, e diretamente por intermédio da influência visigótica na Península ibérica; da moral cristã que assinala estes dois milênios; e da tendência autonomista e liberal dos tempos modernos, especialmente no século XX, marcado por duas guerras mundiais que na vida da família deixaram sinais inapagáveis ${ }^{15}$.

No direito comum o conceito de família abrange a totalidade de pessoas com vínculo consanguíneo, de um tronco ancestral comum e aquelas ligadas por afinidade ou pela adoção. Assim sendo, compre-

13 PEREIRA, Caio Mário da Silva, Instituições de direito civil, Forense, Rio de Janeiro, 2010, p. XI.

14 GONÇALVEZ, Carlos Roberto, Direito civil, p. 17.

15 PEREIRA, Instituições de direito civil, p.13. 
ende os cônjuges e companheiros, os parentes e os afins ${ }^{16}$. Para fins especialmente sucessórios, o conceito de família limita-se aos parentes consanguíneos em linha reta e aos colaterais até o quarto grau.

A principal finalidade do direito de família é tutelar. Direcionase a proteger a família, os bens que lhe são próprios, a prole e muitos outros interesses afins ${ }^{17}$.

O ilustre jurista romano, Cícero (106 - 43 aC.), apelidou a família como seminarium reipublicae, porque entendia que, efetivamente, onde e quando a família mostrou-se forte, aí floresceu o Estado; onde e quando revelou-se frágil, aí começou a decadência social ${ }^{18}$.

A organização familiar romana era fundamentalmente diferente da moderna. Importante essa menção porque o atual sistema de direito repousa suas bases no antigo direito romano e a Igreja Católica foi, decididamente, parte da estrutura do Império romano.

Para os romanos o termo família tinha vários significados: "designava precipuamente o chefe da família e o grupo de pessoas submetido ao poder dele; mas podia também significar patrimônio familiar ou determinados bens a este pertencentes"19.

Vale lembrar que o significado etimológico da palavra família prende-se a famulus, escravo, que, em Roma, tinha obviamente valor econômico. E na sua acepção original, família era proprio iure, isto é, grupo de pessoas sujeitas ao poder do pater familias ${ }^{20}$.

Os membros de uma família são unidos pelo vínculo do parentesco e ele era, no direito romano arcaico, puramente jurídico. $\mathrm{O}$ parentesco consangüíneo, como nos dias de hoje, foi também reconhecido pelo direito romano, acarretando impedimento matrimonial e outras consequências jurídicas. O parentesco não era reconhecido além do $7^{\circ} \operatorname{grau}^{21}$.

\section{GONÇALVEZ, Direito civil, p.1}

17 RIZZARDO, Arnaldo, Direito de família. $8^{\mathrm{a}}$ ed., Forense, Rio de Janeiro, 2011, p. 2

18 TAVARES DA SILVA, Regina Beatriz, Curso de direito civil: direito de família. Washington de Barros Monteiro, 40a ed., Saraiva, São Paulo, 2010, p. 15

19 MARKY, Thomas, Curso elementar de direito romano, $8^{\mathrm{a}}$ ed., Saraiva, São Paulo, 1995, p. 153.

20 MARKY, Curso elementar de direito, p. 153.

21 Digesto, 38.X.4. PR., in MARKY, Thomas, Curso elementar de direito, p. 154. 
A união duradoura entre marido e mulher, como base do grupo familiar (nuptiae, matrimonium), é a ideia fundamental no direito romano. Encontramos um conceito no Digesto de Justiniano uma concepção da época clássica, "muitas delas refletindo concepções ou tendências filosóficas ou religiosas: Nuptiae sunt coniunctio maris et feminae et consortium omnis vitae, divini et humani iuris communicatio ${ }^{, 22} 23$.

A nossa ideia de matrimônio, contudo, baseia-se nos conceitos da ética e teologia cristã, sendo diferente da concepção romana.

No direito romano o matrimônio é considerado como um fato social e não como uma relação jurídica, mesmo tendo consequências jurídicas. "O matrimônio romano era um ato consensual e contínuo de convivência. Era uma res facti e não uma res iuris." 24 . Para eles, havia um acordo contínuo entre os cônjuges, para viverem em comum, com a finalidade de realizar uma união duradoura entre si. Deste modo distinguiram-se, normalmente, dois elementos constitutivos do matrimônio: "a affectio maritalis (intenção de ser marido e mulher) e o honor matrimoii (a realização condigna dessa convivência conjugal). Desse conceito romano, seguem-se a possibilidade do divórcio e até a grande facilidade dele. ${ }^{25}$.

Nesse passo, desaparecendo o consenso, o matrimônio dissolviase, por não existir mais o ato contínuo. "E isso podia acontecer não pelo dissenso (ato bilateral), mas também pela vontade unilateral de um dos cônjuges (repúdio), com base na concepção liberal e individualista que os romanos tinham do casamento"26.

O desaparecimento da afeição era, deste modo, causa necessária e suficiente à dissolução. "Os canonistas, no entanto, opuseram-se à dissolução do vínculo, pois consideravam o casamento um sacramento, não podendo dissolver a união realizada por Deus: quod Deus conjuxit hom non separet" ${ }^{\text {,27 }}$.

\footnotetext{
GONÇALVEZ, Direito civil, p. 21.

23 MARKY, Curso elementar de direito, p. 159.

24 MARKY, Curso elementar de direito, p. 160.

25 MARKY, Curso elementar de direito, p. 160.

26 MARKY, Curso elementar de direito, p. 161.

27 GONÇALVEZ, Direito civil, p. 16.
} 
Embora tendo este viés, o matrimônio, segundo os romanos, era um instituto jurídico, decorrendo dele consequências jurídicas. "Os filhos de cônjuges romanos eram cidadãos romanos também, sujeitos ao poder dos pais, adquirindo a situação de sui iuris após a morte dele, dentre outros efeitos"

Segundo Gonçalves,

(...) o direito de família constitui o ramo do direito civil que disciplina as relações entre pessoas unidas pelo matrimônio, pela união estável ou pelo parentesco, bem como os institutos complementares da tutela e curatela,visto que, embora tais institutos de caráter protetivo ou assistencial não advenham de relações familiares, tem, em razão de sua finalidade, nítida conexão com aquele ${ }^{29}$.

Os três setores em que o direito de família atua, portanto, são as relações pessoais, patrimoniais e assistenciais ${ }^{30}$.

Para Pereira, em sentido genérico e biológico, considera-se por família "o conjunto de pessoas que descendem do mesmo tronco ancestral comum, acrescentando-se o cônjuge, aditando-se os filhos do cônjuge (enteados), os cônjuges dos filhos (genros e noras), os cônjuges dos irmãos e os irmãos do cônjuge (cunhados)". O doutrinador afirma que, na largueza desta noção, os civilistas enxergam mais a figura da romana Gens ou da grega Genos do que da família propriamente dita ${ }^{31}$.

Até podemos perceber que nem sempre os conceitos de família, como exposto pelo direito comum e pelo direito romano, coincidem com o conceito de família proposto pelo magistério da Igreja Católica e pela canonística.

Com muita ênfase fora ratificado pelo Pontifício Conselho para a Família, no documento "Família, matrimônio e união de fato", ano 2000, que a verdadeira família é fundada sobre o matrimônio: "A família que tem por base o matrimônio é um bem fundamental e precio-

\footnotetext{
MARKY, Curso elementar de direito, p. 161.

GONÇALVEZ, Direito civil, p. 19.

GONÇALVEZ, Direito civil, p. 19.

PEREIRA, Instituições de direito civil, p. 23.
} 
so para a sociedade inteira, cujos entrelaces mais firmes estão sob os valores que se manifestam nas relações familiares, que encontram sua garantia no matrimônio estável." É que a união de fato constitui um grande alerta: "Tudo isto se vê comprometido com o abandono da instituição matrimonial, implícito nas uniões de fato."

Sanciona ainda o documento:

A comunidade familiar nasce do pacto de união dos cônjuges. O matrimônio que surge deste pacto de amor conjugal, não é uma criação do poder público, mas uma instituição natural e originária que o precede. Nas uniões de fato, ao contrário, é posto em comum o afeto recíproco, mas ao mesmo tempo falta aquele vínculo conjugal de natureza pública e originária, que funda a família ${ }^{32}$.

Diferente do que se constata da atual jurisprudência no direito comum, família e vida formam uma verdadeira unidade, que deve ser protegida pela sociedade, posto ser o núcleo vivo da sucessão (procriação e educação) das gerações humanas.

$\mathrm{Na}$ base da reflexão está a definição dada pelo Catecismo da Igreja sobre família: "a célula originária da vida social. É a sociedade natural, na qual o homem e a mulher são chamados ao dom de si no amor e no dom da vida" $" 33$.

Como dito, esse modo de enxergar o fenômeno sociológico que constitui a família alcança, na época contemporânea, visões e conceitos tão amplos, que tantas vezes não só vão além do modo cristão de pensar a família, como substancialmente contrastam e rejeitam essa visão.

Analisa assim o doutrinador Silvio de Salvo Venosa: "os conflitos sociais gerados pela nova posição social dos cônjuges, as pressões econômicas, a desatenção e o desgaste das religiões tradicionais fazem aumentar o número de divórcios" ${ }^{34}$.

32 PONTIFICIO CONSIGLIO PER LA FAMIGLIA, Familia, matrimonio $e$ “unioni di fatto", Tradução nossa, Paoline, Milano, 2000, p. 20.

33 CATECISMO DA IGREJA CATÓLICA, n. 2207, $9^{a}$ ed., Loyola, Vozes, Paulinas, Ave Maria, Paulus, São Paulo, 1998, p. 576.

34 VENOSA, Sílvio de Salvo, Direito civil: direito de família, $9^{a}$ ed. Atlas, São Paulo, 2009, p. 6. 
Acrescenta que "a unidade familiar, sob o prisma social e jurídico, não mais tem como baluarte exclusivo o matrimônio", fazendo surgir, por estes e outros motivos, um novo direito de família, com surpresas e desafios trazidos pela ciência ${ }^{35}$.

Em cada época histórica a vida doméstica assume formas específicas e com métodos próprios ${ }^{36}$; e, nos dias atuais, seu conceito assume significados diversos.

Donati, filósofo e sociólogo italiano, citato por Porreca ${ }^{37}$, na proposta de uma "sociologia relacional", propõe algumas teorias mediante determinadas abordagens:

1. Abordagem institucional, considerando a família essencialmente como instituição social, isto é, grupo social que deve ter uma precisa estruturação normativa publicamente sancionada;

2. Abordagem estrutural/funcionalista: a análise recai não na instituição, mas sim como um sistema social familiar, uma pequena sociedade, como estrutura de tarefas, que deve se ocupar de funções especiais como um todo, sociedade definida como um sistema global que se mantém funcionalmente unida com todos os outros sistemas da sociedade;

3. Abordagem das trocas: o modelo familiar não pode ser baseado na conformidade de tarefas, nem no consenso aos valores últimos. Considera-se o comportamento uma troca complexa de atividades mutuamente recompensadoras, em que cada membro aceita e mantém um benefício, desde que possa restituir e retribuir a outro membro. (Curioso aqui lembrar, no antigo direito grego, que no código de Sólon, séc. VI a.C., que sanciona que os pais que não ensinassem aos filhos um ofício estariam desobrigando-os de os tratarem na velhice.)

4. Abordagem interacionista: família como unidade de pessoas, interagindo entre si, sem preocupação com a análise dos vínculos legais ou institucionais, nem no âmbito da vida conjugal;

35 VENOSA, Direito civil, p. 6.

36 JOSÉ FILHO, 2002; DURHAM, 1983; LÉVI-STRAUSS, 1969, in PORRECA, Wladimir, Famílias em segunda união: questões pastorais, $3^{\mathrm{a}}$ ed., Paulinas, São Paulo, 2013, p. 55.

37 PORRECA, Famílias em segunda união, pp. 55-67. 
5. Abordagem marxista: família como instituição social monogâmica, um produto histórico, nascido com a propriedade privada dos meios de produção e que encontra no Estado a sua garantia;

6. Abordagem da teoria crítica: família como uma forma social ambivalente: de um lado é funcional, por controlar a ordem sociocultural, de outro é necessária ao amadurecimento do indivíduo;

7. Abordagem hermenêutico-fenomenológica: acentua os elementos significativos e intencionais, subjetivos e intersubjetivos. Tudo nela é símbolo que requer interpretação, a qual parte da cultura e não do indivíduo; um agir do sujeito ente sujeitos;

8. Abordagem do desenvolvimento: mostra a configuração familiar; seus modelos se modificam no tempo e segundo as fases do ciclo de vida em que a família se encontra;

9. Abordagem feminista: introduz a ótica do gênero para examinar a realidade familiar-social, para saber como os membros da família vêm se relacionando. Ao exigir uma forma de igualdade entre homem e mulher, deixa esvair a identidade específica de cada um deles e, de outro lado, quando afirma uma diferença de gênero, leva a legitimar uma nova desigualdade, não só entre homem e mulher, mas também no interior do mesmo mundo feminino.

10. Abordagem relacional: Donati, considerando incompletas as abordagens acima elencadas, propõe a família como lugar privilegiado de relações de reciprocidade e confiança. É uma relação social e não meramente biológica ou psicológica, dotada de características próprias, únicas e insubstituíveis; uma relação sui generis.

A família consiste em ter uma realidade entrelaçada de elementos objetivos e subjetivos, que transcendem as coisas já dadas. Mesmo com as manifestações de algumas problemáticas atuais, como diminuição dos matrimônios, crescentes separações e divórcios e as emergentes outras formas de ser família, nada a elimina $^{38}$.

38 PORRECA, Famílias em segunda união, p. 66. 
Segundo o estudo do Wladimir Porreca, a partir da segunda metade dos anos 60, a família é vista como sujeito/objeto do processo de modernização. No início dos anos 70 , a situação é um pouco contrária, pois é entendida como uma realidade que se dissolve. A partir dos anos 80 até hoje, com o emergente clima cultural, passa a ser encarada como um modo ideologizante, como um fenômeno de pura comunicação ${ }^{39}$.

Donati assevera ainda, que o problema social da família esteja no sentido da sua relação constitutiva. Alguns estudos contemporâneos afirmam que não existe mais a família, mas que há muitas e diversas famílias ${ }^{40}$.

No sentido técnico de família, Ferrara, citado por Diniz, explica que ela é entendida pela doutrina jurídica civil como "grupo fechado de pessoas, composto dos pais e filhos e, para efeitos limitados, de outros parentes, unidos pela convivência e afeto numa mesma economia e sob a mesma direção" ${ }^{\text {. }}$.

Vários são os caracteres da família: o biológico, psicológico, econômico, religioso e o político ${ }^{42}$.

Assim sendo, verificamos espécies de família na doutrina jurídica civil:

1. A matrimonial: baseada no casamento;

2. A não-matrimonial: oriunda de relações extraconjugais;

3. Adotiva: estabelecida por adoção que, juntamente com a guarda e tutela, configurará a família substituta;

4. Monoparental: formada por um dos genitores e a prole;

5. Anaparental: formada por irmãos uns com os outros, sem que haja hierarquia entre as gerações;

6. Eudemônica: formada por laços de afeto. Esta tipologia começa a aparecer nas certidões de nascimento constando, por exemplo, quatro pais (duas mães e dois pais) e consequente-

\footnotetext{
39 PORRECA, Famílias em segunda união, pp. 44-54.

40 PORRECA, Famílias em segunda união, p. 67.

41 FERRARA, Trattato di direitto civile italiano, p. 547 in DINIZ, Maria Helena, Curso de Direito Civil Brasileiro, vol. 5, Direito de Família. 25 a ed., Saraiva, São Paulo, 2010, p. 12.

42 DINIZ, Curso de Direito Civil, pp. 13-15.
} 
mente, oito avós. Neste caso denomina-se como multiparentalidade ou pluriparentalidade.

O legislador brasileiro entende o casamento como uma união legal entre um homem e uma mulher, com o objetivo de constituírem a família legítima. Reconhece o efeito de estabelecer "comunhão plena de vida, com base na igualdade de direitos e deveres dos cônjuges" (C. Civil art. 1511) $)^{43}$.

A união estável, reconhecida pela Constituição Federal de 1988, e pelo Código Civil (art. 1723) como entidade familiar, pode ser considerada de família natural ${ }^{44}$.

Quando formada por somente um dos pais e seus filhos, denomina-se família monoparental (C.R 88, art 226, § 4. $)^{45}$. Venosa discorrerá acerca de elementos que do estado de família derivam, especificando ainda mais a distinção de suas características ${ }^{46}$.

Em 1977, deixando de lado a máxima cristã do que "o que Deus uniu o homem não separa", o legislador brasileiro admite o divórcio.

Contudo, a Resolução 175, de 14 de maio de 2013, do Conselho Nacional de Justiça, dispôs sobre a habilitação do casamento civil ou de conversão de união estável em casamento entre pessoas do mesmo sexo, considerando a Ação Direta de Inconstitucionalidade 4277/DF.

43 PEREIRA, Instituições de direito civil, p. 64.

44 PEREIRA, Instituições de direito civil, p. 41.

45 VENOSA, Direito civil, p. 22.

$46 \mathrm{O}$ estado de família apresenta características distintas que se traduzem em: 1 . Intrasmissibilidade: este status não se transfere por ato jurídico, nem entre vivos, nem por causa de morte; 2. Irrenunciabilidade: ninguém pode despojar-se por vontade própria de seu estado. Ninguém pode renunciar ao pátrio poder; 3 . Iprescritibilidade: o estado de família, por sua natureza, é imprescritível, como decorrência de seu caráter personalíssimo. Não se pode adquirir por usucapião, nem se perde pela prescrição extintiva; 4. Universalidade: é universal porque compreende todas as relações jurídico-familiares; 5. Indivisibilidade: o estado de família é indivisível, de modo que será sempre o mesmo perante a família e a sociedade. Não se permite, portanto, que uma pessoa seja considerada casada para determinadas relações e solteira para outras; 6 . Correlatividade: o estado de família é recíproco, porque se integra por vínculos entre pessoas que se relacionam. Desse modo, ao estado de marido antepõe-se o de esposa; ao de filho, o de pai, e assim por diante; 7. Oponibilidade: é oponível pela pessoa perante todas as outras. O casado assim é considerado perante toda a sociedade. (VENOSA, 2009, p. 18) 
De outro lado, foi aprovado em 24 de setembro de 2015, o Estatuto da Família, por uma comissão especial da Câmara Federal, que, no seu artigo segundo reza: "define-se entidade familiar como o núcleo social formado a partir da união entre um homem e uma mulher, por meio de casamento ou união estável, ou ainda por comunidade formada por qualquer dos pais e seus descendentes." Este Estatuto ainda encontra-se em tramite.

O que se pode constatar é que a legislação positivada, não raro, encontra percalços na normatização dos aspectos humanos como a família e debruça-se em grandes debates na arena da ética, e até mesmo, na compreensão da justiça.

A Igreja Católica apoia o conceito de família fundado no matrimônio, "aliança pela qual o homem e mulher constituem entre si uma comunhão de toda a vida", superando a legislação pio-beneditina e definindo-o como "foedus" pacto, aliança, extrapolando a mera tendência civilista de contrato ${ }^{47}$.

Isso não significa que este pacto não seja contrato, como sanciona o mesmo legislador canônico no cânon $1096 \S 1$. Este é sacramento, sem deixar de ser, ao mesmo tempo, contrato. Contrato peculiar quanto à origem, explica Hortal, porque possui fins próprios e não apenas aos contraentes: quanto à dignidade, porque o matrimônio é um contrato sagrado, de caráter religioso; mesmo quando se trata da união entre dois não-batizados - através do batismo, a legislação canônica entende que alguém se torna sujeito de direitos e deveres como reza o cânon 96 - nele se celebra o mistério da vida e o poder de transmiti-la, que Deus deu à sua criatura; quanto ao objeto, às propriedades e aos efeitos principais, determinados pela natureza humana, em que nem a vontade das partes, nem a autoridade pública, possa modificá-los; e, em razão da estabilidade, tem duração perpétua, pela sua própria natureza. Esses elementos levaram muitos canonistas a abandonarem a teoria do contrato e a substituí-la pela da instituição ${ }^{48}$.

O Concílio Vaticano II dedicou-se, com particular apreço, à temática em questão, trazendo a lume conceitos da família e de sua mis-

47 CIC-1983, cân. 1055.

48 HORTAL, Jesus, $O$ que Deus uniu. $8^{\mathrm{a}}$ ed., Edições Loyola, São Paulo, 2012, p. 23. 
são no mundo como: célula primeira e vital da sociedade Apostolicam Actuositatem, 11; fonte da vida social Gaudium et Spes 32; vínculo social, Gaudium est Spes 25; necessidade da família de uma comunidade mais ampla Gaudium et Spes 74; primeira escola das virtudes sociais que todas as sociedades necessitam Gravissimum Educationis 3; do consórcio matrimonial procede a família, da qual nascem novos cidadãos da sociedade humana, Lumen Gentium 11b; lugar da primeira experiência quer da sã sociedade humana, quer da Igreja Gravissimum Educationis 3; promotora da justiça e demais obras boas a serviço de todos os irmãos constituídos em necessidade Apostolicam Actuositatem, 11 , dentre outros ${ }^{49}$.

Com insistência, a Igreja no Brasil recorda a todos os desafios do nosso tempo neste contexto de "mudança de época". As últimas diretrizes da ação evangelizadora, de fato, no caminho do Documento de Aparecida e na carta magna do atual Pontífice a Evangelii Gaudium apresentam alguns riscos: "mudanças de época, de fato, afetam os critérios de compreensão, os valores mais profundos, a partir dos quais se afirmam identidade e se estabelecem ações e relações" $" 50$.

Isso faz pensar que as consequências atingiram, sobremodo, a família:

(...) constata-se o aumento progressivo do relativismo, a ausência de referências sólidas, o excesso de informações, a superficialidade, o desejo a qualquer custo de conforto e facilidade, a aceleração do tempo, trazendo desafios existenciais e produzindo incertezas, precariedade, insegurança, inquietação... A atual crise cultural atinge, de modo particular, a família. Difunde-se a noção de que a pessoa livre e autônoma precisa se libertar da família, da religião e da sociedade" $" 51$.

49 COMPÊNDIO DO VATICANO II, Constituições, decretos, declarações, $25^{\mathrm{a}}$ ed., Vozes, Petrópolis, 1996.

50 CONFERÊNCIA NACIONAL DOS BISPOS DO BRASIL, Diretrizes gerais da ação evangelizadora da Igreja no Brasil: 2015-2019, Edições CNBB, Brasília, 2015 , p. 25

51 Evangelii Gaudium, nn.66-67 in CONFERÊNCIA NACIONAL DOS BISPOS DO BRASIL, Diretrizes gerais da ação evangelizadora da Igreja no Brasil: 2015-2019, Edições CNBB, Brasília, 2015, p. 25. 
Nem de menos se pode esquecer de ilustrar os avanços e conquistas no contexto atual: a promoção da mulher; a valorização das minorias étnicas; o destaque à justiça, à paz e à ecologia; as iniciativas da superação da miséria e da fome e o a contribuição, no mundo das ciências e da técnica, que proporciona conforto e bem-estar ${ }^{52}$.

O Papa Francisco deseja uma Igreja que saia pelas estradas e que vá ao encontro, à procura dos excluídos, com um desejo inesgotável de oferecer misericórdia ${ }^{53}$.

E essa é a Igreja, a vinha do Senhor, a Mãe fecunda e a Mestra solícita, que não tem medo de arregaçar as mangas para derramar o azeite e o vinho sobre as feridas dos homens (cf. $L c$ 10, 25-37); que não observa a humanidade a partir de um castelo de vidro, para julgar ou classificar as pessoas. Esta é a Igreja Una, Santa, Católica, Apostólica e formada por pecadores necessitados da sua misericórdia. Esta é a Igreja, a verdadeira Esposa de Cristo, que procura ser fiel ao seu Esposo e à sua doutrina. É a Igreja que não tem medo de comer e beber com as prostitutas e os publicanos (cf. $L c, 15$ ).

A Igreja que tem as suas portas escancaradas, para receber os necessitados, os arrependidos e não apenas os justos ou aqueles que se julgam perfeitos! A Igreja que não se envergonha do irmão caído, nem finge que não o vê; antes, pelo contrário, sente-se comprometida e quase obrigada a levantá-lo e a encorajá-lo a retomar o caminho, acompanhando-o rumo ao encontro definitivo, com o seu Esposo, na Jerusalém celeste.

O Pontífice atual convocou um Sínodo para tratar os desafios pastorais da família no contexto da evangelização com uma Assembleia Geral Extraordinária (2014) e pela Ordinária (2015). Percebe-se, neste contexto, com meridiana clareza, a vontade da Igreja de colocar o seu olhar, com maior acolhida, sobre as outras formas de arranjos familiares presentes no atual contexto.

CONFERÊNCIA NACIONAL DOS BISPOS DO BRASIL, Diretrizes gerais, p. 24.

53 PAPA FRANCISCO, Evangelii Gaudium, A alegria do evangelho, Paulinas, São Paulo, 2013, pp. 42-43 
Reflete-se sobre a possibilidade dos divorciados e recasados terem acesso aos sacramentos da penitência e da Eucaristia, mesmo após a Exortação Pós-sinodal Amoris Laetitia ${ }^{54}$.

Faz-se necessário ter presente a distinção entre situação objetiva de pecado e circunstâncias atenuantes, visto que a "imputabilidade e a responsabilidade de uma ação podem ficar diminuídas ou suprimidas" por diversos "fatores psíquicos ou sociais" (CIC 1735); caberá ainda maior reflexão para casos concretos.

A Igreja proposta por Francisco apresenta-se como "Mãe de coração aberto", "casa aberta do Pai" ao mundo ${ }^{55}$.

A pedido dos bispos sinodais, tem-se a última reforma do processo de declaração de nulidade matrimonial, através do Moto Proprio "Mitis Judex, Dominus Iesus", simplificando o processo de nulidade matrimonial, com garantia da certeza moral do primeiro juízo a norma do direito, sem a necessidade de uma dupla sentença conforme, (tema altamente discutido na esfera canônica, à vista da necessidade de tutela da indissolubilidade e unidade do matrimônio sacramento) e criando um "processus brevior". Alguns juristas preferiam o termo "extraordinário" no lugar de "breve", para melhor indicar a natureza do instituto - nos casos da nulidade acusada com argumentos particularmente evidentes tais como: a falta de fé que pode gerar simulação do consentimento, a brevidade da convivência conjugal, a obstinada permanência em uma relação extraconjugal anterior e posterior às núpcias, $\mathrm{o}$ ocultamento doloso da esterilidade ou de uma grave enfermidade contagiosa, ou de filhos nascidos de uma precedente relação, causas estranhas à vida conjugal ou consistentes de uma gravidez imprevista, entre outras (MIDI, Art. 14, $\S 1$ ). Esse processo torna mais evidente, segundo o ensinamento do Concílio, a figura do Bispo como juiz para os fiéis a ele confiados.

No dia 25 de novembro de 2017 o atual Pontífice firmou pontos importantes acerca do processo breve, asseverando que este "não é

54 PAPA FRANCISCO. Amoris Laetitia. A Alegria do Amor, Números 301-303, Editora Canção Nova, Cachoeira Paulista, 2016, pp. 189-191. CONFERÊNCIA NACIONAL DOS BISPOS DO BRASIL, Acolhida da Exortação Apostólica Amoris Laetitia pela Igreja no Brasil. Coleção Sendas, vol. 9, Edições CNBB, Brasília, 2017.

55 PAPA FRANCISCO, Evangelii Gaudium, pp. 40-41. 
uma opção, mas uma obrigação que o Bispo recebe de sua consagração. Ele é o único competente nas três fases do processo: a instância, a fase instrutória e a decisão coram Domino". Lembrou, ainda, que a misericórdia é um dos critérios fundamentais que asseguram a 'salus'; requer, nesse sentido, que "o bispo diocesano atue o quanto antes no processo 'breviore'; e, no caso em que não se considere pronto, deve adiar a causa ao processo ordinário que, todavia, deve ser conduzido com a devida solicitude" ${ }^{, 56}$.

Evidentemente os riscos de abuso na aplicação da nova norma são reais, (não poucos falam de um "divórcio católico"); contudo, há clareza em relação à preocupação em tutelar os elementos fundantes do matrimônio cristão e em tutelar a unidade na fé, na disciplina do matrimônio, ponto cardeal e origem da família Cristã ${ }^{57}$.

No Brasil caminha a efetivação do Acordo entre Brasil e Santa Sé, com possibilidade de homologação das sentenças eclesiásticas em matéria matrimonial, como homologação de sentenças estrangeiras. (Art. $12 \S 1$ ).

É claro que toda a reflexão pós conciliar, acerca da família, e que nos chega hoje, encontra, nos tempos atuais, desafios objetivos a se afrontar. O sistema parcial familiar transformou-se em característica decisiva, numa qualidade das relações sociais que está em franca oposição à pura referência institucional.

Pergunta Mette: "apresentar a família como célula da sociedade - entendida à vista de uma importância biológica e moral básica - é um ideal que tem sentido ser defendido? Mais ainda nessa sociedade, onde a família vive uma crise institucional profunda?"58.

Igualmente, autores sugerem a necessidade de ver a família não somente como "Igreja doméstica", visto que esta denota caráter institucional de família católica e "fortaleza de Deus" contra as tendências

56 PAPA FRANCISCO, Discorso del Santo Padre Francesco ai partecipanti al corso promosso dal Tribunale della Rota Romana, 25.11.2017. Internet. Disponível em: http://w2.vatican.va/content/francesco/it/speeches/2017/november/ documents/papa-francesco_20171125_corso-rotaromana.html

57 PAPA FRANCISCO, Mitis Iudex Döminus Iesus e Misericors Iesus, Edições CNBB, Brasília, 2015, pp. 8-9.

58 METTE, família, in MATTOS, Dicionário do ConcílioVaticano II, Paulus, São Paulo, 2015, p. 378. 
de liberalização e pluralização, com expectativa de que venha a ser o lugar confiável da reprodução da Igreja. Mattos apresenta o desafio da necessidade de uma fundamentação doutrinal mais consistente, que considere os desafios atuais no contexto societário. ${ }^{59}$

\section{Conclusão}

Concluindo, acredita-se necessário redescobrir a família, no modo em que propuseram Auer e Ratzinger ${ }^{60}$ como espaço humano para o cuidado natural e garantia das relações inter-humanas, reconhecendo, em cada membro desta comunidade, pessoa livre e única. Assim, cada indivíduo, enquanto membro de um todo maior, em uma relação sã consigo mesmo e com os outros. A família, enquanto espaço do grande amor natural e da amizade, é o húmus natural e originário para o desenvolvimento da maturação necessária e sã confiança em si mesmo, como também da necessária e sã confiança do amor ao próximo.

A proposta seria apresentar e incentivar o caminho de família, na atual conjuntura, na sua dimensão humanizadora (GS 47, 52), ou seja, de lugar humano onde se transmitem valores ou se vive uma experiência humana que possibilita o "enriquecimento humano" (GS 52).

No discurso proferido na Assembleia Ordinária do Sínodo, em 5 de outubro de 2015, o Papa Francisco pediu: "coloquemos diante de nossos olhos o bem da Igreja, da família, e a suprema lex, a salus animarum".

Se "a coragem apostólica de levar vida e não fazer da nossa vida cristã um museu de recordações", bem como "evangelizar que é, em primeiro lugar, dar testemunho" $(\mathrm{EG}, 26)$ a família cristã deverá encontrar, no mundo, seu lugar legítimo. O atual Pontífice vê na família um pilar fundamental que sustenta uma nação, como bem imaterial. Ela permanece na base da convivência, como garantia contra a desin-

59 MATTOS, família, Dicionário do Concílio Vaticano II, p. 378.

60 AUER, Johann; RATZINGER, Joseph, I Sacramenti della Chiesa, 2a ed., Vol. 7. Cittadella Editrice, Assisi,1989, p. 301 
tegração social. Vendo o "matrimônio como um contributo que supera o nível da afetividade e das necessidades contingentes do casal"61.

E, por fim, a própria Igreja, de maneira cada vez mais evidente, é vista como lugar humano de convivência dos filhos de Deus e como família. Cabem as palavras do Papa neste sentido:

$\mathrm{Na}$ "Galileia dos gentios" do nosso tempo, voltaremos a encontrar a espessura duma Igreja que é mãe, capaz de gerar para a vida e cuidadosa em dar continuamente a vida, em acompanhar com dedicação, ternura e força moral. Porque, se não soubermos unir a compaixão à justiça, acabaremos por sermos inutilmente severos e profundamente injustos.

Uma Igreja, que é família, sabe apresentar-se com a proximidade e o amor de um pai, que vive a responsabilidade do guardião, que protege sem substituir, que corrige sem humilhar, que educa com o exemplo e a paciência... e, por vezes, simplesmente com o silêncio de uma expectativa orante e aberta.

Sobretudo, uma Igreja de filhos que se reconhecem irmãos, nunca chega a considerar alguém apenas como um fardo, um problema, um custo, uma preocupação ou um risco: o outro é essencialmente um dom, que continua a ser tal mesmo quando percorre estradas diferentes ${ }^{62}$.

A Exortação pós-sinodal, já citada, a Amoris Laetitia ${ }^{63}$, reafirma a importância do matrimônio cristão na formação da família, sua indissolubilidade; contudo, abrindo uma reflexão real no campo de ação concreta, em que a vida familiar não se realiza perfeitamente ou não se desenvolve em paz e alegria. Também outras estruturas que compõem comunidades de pessoas deverão estar na mira da ação pastoral.

Certos de que nesta seara, em que o matrimônio e a família estão há, aí mesmo, um núcleo de tensão onde se entrecruzam o mundo e o

61 PAPA FRANCISCO, Discurso Papa Francisco aos participantes do encontro internacional sobra a complementaridade entre homem e mulher. Internet. Disponível em: http://w2.vatican.va/content/francesco/pt/speeches/2014/november/ documents/papa-francesco_20141117_congregazione-dottrina-fede.html PAPA FRANCISCO, Discurso do Papa Francisco na Vigília de oração em preparação para o Sínodo. Internet. Disponível em: https://w2.vatican.va /content/francesco/pt/speeches/2015/october/documents/papafrancesco_2015100 3 _veglia-xiv-assemblea-sinodo.html.

63 PAPA FRANCISCO, Amoris Laetitia, pp. 81-84. 
mistério, o poder secular e o fenômeno religioso, o direito continuará cumprindo seu papel de uma aspiração ética da norma positiva, que o condiciona à prioridade do problema do justo ${ }^{64}$ do homem para o homem, no necessário fato de devermos dar a César o que é de César e a Deus o que é de Deus ${ }^{65}$.

\section{BIBLIOGRAFIA}

\section{Fontes}

CATECISMO DA IGREJA CATÓLICA, $9^{\text {a }}$ ed., Loyola, Vozes, Paulinas, Ave Maria, Paulus, São Paulo, 1998.

CÓDIGO DE DIREITO CANÔNICO, $9^{\mathrm{a}}$ ed., Edições Loyola, São Paulo, 2008.

COMPÊNDIO DO VATICANO II, Constituições, decretos, declarações, $25^{\text {a }}$ ed., Vozes, Petrópolis, 1996.

CONFERÊNCIA NACIONAL DOS BISPOS DO BRASIL, Diretrizes gerais da ação evangelizadora da Igreja no Brasil: 20152019, Edições CNBB, Brasília, 2015.

, Acolhida da Exortação Apostólica Amoris Laetitia pela Igreja no Brasil. Coleção Sendas, vol. 9, Edições CNBB, Brasília, 2017.

DICIONÁRIO DO CONCÍlIO VATICANO II, Paulus, São Paulo, 2015.

PONTIFICIO CONSIGLIO PER LA FAMIGLIA, Familia, matrimonio e "unioni di fatto", Paoline, Milano, 2000.

\footnotetext{
64 LITRENTO, Oliveiros, Curso de filosofia do direito, Editora Rio, Rio de Janeiro, 1980 , p. 19

65 Mc 12, 13-17, Mt 22,15-22, Lc 20, 20-26.
} 


\section{Autores}

AUER, Johann; RATZINGER, Joseph, I Sacramenti della Chiesa, $2^{\mathrm{a}}$ ed., Vol. 7. Cittadella Editrice, Assisi,1989.

BARAUNA, Guilherme, A Igreja do Vaticano II, Vozes, Petrópolis Rio de Janeiro, 1965.

DALLA TORRE, Giuseppe, La città sul monte, Contributo ad uma teoria canonistica sulle relazioni fra Chiesa e Comunità politica, $2^{\mathrm{a}}$ ed., Editrice Ave, Roma, 2002.

DINIZ, Maria Helena, Curso de Direito Civil Brasileiro, vol. 5, Direito de Família. 25 ed., Saraiva, São Paulo, 2010.

GONÇALVEZ, Carlos Roberto, Direito civil brasileiro: Direito de Família, Vol. 6., Saraiva, São Paulo, 2006.

HORTAL, Jesus, $O$ que Deus uniu. $8^{\text {a }}$ ed., Edições Loyola, São Paulo, 2012.

JOÃO PAULO II, Familiaris Consortio: A missão da família cristã no mundo de hoje, Paulinas, São Paulo, 1981.

, Novo Millennio Ineunte, $6^{\mathrm{a}}$ ed., Paulus, Edições Loyola, São Paulo, 2001.

LITRENTO, Oliveiros, Curso de filosofia do direito, Editora Rio, Rio de Janeiro, 1980.

MARKY, Thomas, Curso elementar de direito romano, $8^{\mathrm{a}}$ ed., Saraiva, São Paulo, 1995.

PAPA FRANCISCO. Amoris Laetitia. A Alegria do Amor, Editora Canção Nova, Cachoeira Paulista, 2016.

, Discorso del Santo Padre Francesco ai partecipanti al corso promosso dal Tribunale della Rota Romana, 25.11.2017. Internet. Disponível em: http://w2.vatican.va/content/francesco/it/ speeches/2017/november/documents/papafrancesco_20171125_ corso-rotaromana.html)

, Discurso do Papa Francisco na Vigília de oração em preparação para o Sínodo. Internet. Disponível em: https://w2.vatican. 
$\mathrm{va} /$ content/francesco/pt/speeches/2015/october/documents/papafrancesco_20151003_veglia-xiv-assemblea-sinodo.html.

, Discurso na Assembleia das Nações Unidas. Internet. Disponível em: http://w2.vatican.va/content/francesco/pt/speeches/ 2015/september/documents/papa-francesco_20150925_onuvisita.html.

, Discurso Papa Francisco aos participantes do encontro internacional sobra a complementaridade entre homem e mulher. Internet. Disponível em: http://w2.vatican.va/content/francesco/pt/ speeches/2014/november/documents/papafrancesco_20141117_ congregazione-dottrina-fede.html

, Evangelii Gaudium, A alegria do evangelho, Paulinas, São Paulo, 2013. , Mitis Iudex Dominus Iesus e Misericors Iesus, Edições CNBB, Brasília, 2015.

PARADISO, Massimo, Corso di Instituzioni di Diritto Privato, G. Giappichelli Editore, Torino, 2001.

PEREIRA, Caio Mário da Silva, Instituições de direito civil, Forense, Rio de Janeiro, 2010.

PORRECA, Wladimir, Famílias em segunda união: questões pastorais, $3^{\text {a }}$ ed., Paulinas, São Paulo, 2013.

RIZZARDO, Arnaldo, Direito de família. $8^{\mathrm{a}}$ ed., Forense, Rio de Janeiro, 2011.

TAVARES DA SILVA, Regina Beatriz, Curso de direito civil: direito de família. Washington de Barros Monteiro, 40 ed., Saraiva, São Paulo, 2010.

TITO LÍVIO, Historia de Roma desde su fundacion - Ab urbe condita - Libro V, Internet. Disponivel em: http://historicodigital.com/ download/tito\%20livio\%20i.pdf.

VENOSA, Sílvio de Salvo, Direito civil: direito de família, 9a ed. Atlas, São Paulo, 2009. 